\title{
Comparative review of human and canine osteosarcoma: morphology, epidemiology, prognosis, treatment and genetics
}

\author{
Siobhan Simpson ${ }^{1}$, Mark David Dunning ${ }^{1}$, Simone de Brot ${ }^{1}$, Llorenç Grau-Roma', Nigel Patrick Mongan ${ }^{1,2^{*}}$ \\ and Catrin Sian Rutland ${ }^{1}$ (C)
}

\begin{abstract}
Osteosarcoma (OSA) is a rare cancer in people. However OSA incidence rates in dogs are 27 times higher than in people. Prognosis in both species is relatively poor, with 5 year OSA survival rates in people not having improved in decades. For dogs, 1 year survival rates are only around $\sim 45 \%$. Improved and novel treatment regimens are urgently required to improve survival in both humans and dogs with OSA. Utilising information from genetic studies could assist in this in both species, with the higher incidence rates in dogs contributing to the dog population being a good model of human disease. This review compares the clinical characteristics, gross morphology and histopathology, aetiology, epidemiology, and genetics of canine and human OSA. Finally, the current position of canine OSA genetic research is discussed and areas for additional work within the canine population are identified.
\end{abstract}

Keywords: Bone cancer, Canine, Genetics, Human, Molecular diagnostics, Osteosarcoma, Treatment

\section{Background}

Cancer is a leading cause of non-communicable morbidity and mortality throughout the world, second only to cardiovascular disease in the number of deaths of adults between the ages of 30 and 70 years old $[1,2]$. For dogs, the most frequent causes of mortality in order are (i) cancer, (ii) trauma, (iii) locomotor (skeletal, muscles and joints), (iv) cardiac disease, and (v) neurological disease [3]. The development of new and superior cancer treatments has long been a priority in medicine, more recently there has been a drive to develop new approaches to treat and manage cancer in companion animals. Indeed, cancer in dogs is increasingly a concern for pet owners, in particular as some types of cancer occur at much higher rates in certain dogs breeds [4-7]. These cases of cancer

\footnotetext{
*Correspondence: Nigel.mongan@nottingham.ac.uk

${ }^{1}$ Faculty of Medicine and Health Sciences, School of Veterinary Medicine and Science, The University of Nottingham, Sutton Bonington Campus, Loughborough LE12 5RD, UK

Full list of author information is available at the end of the article
}

in dogs themselves require treatment, in addition these spontaneous cancers in dogs represent effective models for the human disease equivalent [8]. Although developing new treatments in companion animals with naturally occurring disease is less contentious than inducing disease in experimental animals, ethical concerns with regards to the treatment of individuals enrolled on studies and gaining informed consent from owners remain [9].

Cancer is more common in adults than children, adolescents, and young adults ( $<30$ years old) $[10,11]$. Despite this, bone cancer is most common in the young $(<20$ years old) and elderly (over 60 years old) than individuals of intermediary age (20-60 years old) [10-12]. For many cancer types 5 year survival rates are improving, reflecting the development of earlier diagnostic techniques and improved treatments $[1,13]$. In contrast to many other cancers OSA, the most common bone cancer, has not shown comparable improvements in mortality 
rates [13-15]. There is thus an urgent need to develop improved treatments for OSA.

In both human and canine patients the predominant bone cancer diagnosis is OSA $[15,16]$. OSA is still considered rare in humans. For example, there were 217,440 estimated breast cancer cases in the NIH-NCI surveillance, epidemiology, evidence and end results (SEER) database in 2004 alone, compared to 3482 cases of OSA in the same database between 1973 and 2004 [15, 17]. Although OSA is also not very common in dogs, it is much more common than in people. Norwegian owner questionnaire data from four breeds (Labrador retriever, Newfoundland, Leonberger and Irish wolfhound) showed OSA incidences of between 0.2 and $8.9 \%$ depending on the breed [18]. The percentage of dogs positively identified with OSA in two Polish clinics was estimated to be between 2.7 and 10.7\%, again depending on breed [19]. Between 1995 and 2002 of 394,061 insured Swedish dogs, $764(0.19 \%)$ developed a bone cancer [16]. This is an incidence rate of 27.2 dogs per 100,000 included in the dataset each year. While the canine data only includes insured dogs, it is a large dataset so is likely to be representative of the dog population of the country as whole. In the comparable Swedish population, 234 men and 164 women had bone cancer between 1998 and 2002, which is roughly 0.89 cases of bone cancer per 100,000 people each year [11]. The human data records all bone cancer cases in the country and the average population size between 1998 and 2002 was calculated from government census data. In addition all other countries in the "Cancer Incidence in Five Continents" registry report human incidence rates similar to Sweden $[11,12]$. Thus, the incidence of canine bone cancer is 27 times higher than in humans. The higher incidence rate of canine OSA makes the pet dog population a good model for human disease. While there is potential for any dog to develop OSA, a subset of larger dog breeds are at increased risk of developing OSA [16].

The purpose of this review is to give an insight into the morphology, epidemiology, prognosis, treatment and genetics of osteosarcoma and to compare these aspects, in light of the published literature, between humans and dogs. Such knowledge is required to translate advances made in the clinical management of OSA in people to dogs; and to advance our understanding of where disease processes are similar across species.

\section{Search strategy}

This review is based on a search in PubMed (http://www. ncbi.nlm.nih.gov/pubmed) using the terms "canine, dog, human, osteosarcoma, cancer, tumour, oncology". Each title and abstract of the obtained hits were evaluated and articles referring to genetics, epidemiology, treatment, histology and prognosis were assessed in detail (full text). Searches were carried out from 06/2016 to $02 / 2017$ an additionally $08 / 2017$. All titles, abstracts and full texts were read and obtained by all authors. Searches included web of science and PubMed. All papers published prior to, and including 08/2017 were included. Our personal photograph archives were used to illustrate OSA (with appropriate ethical permissions) and our experience within the field was used to evaluate the literature.

\section{Gross and histological similarities and differences between canine and human OSA}

A sarcoma is a malignant tumour originating in tissues derived from the mesoderm; affecting bone, cartilage and other connective tissues [20]. OSA is a sarcoma which produces bone or osteoid [21]. In both people and dogs, the gross appearance of the OSA is markedly variable, some being predominantly lytic (soft, fleshy and with areas of haemorrhage and necrosis), productive (hard consistency and variably grey in colour), or being a mix of both. It frequently transgresses the cortex at the same time that it grows within the medulla, rarely penetrating the joint (Fig. 1) [22]. World Health Organisation (WHO) defines OSA as a primary malignant bone tumour in which the neoplastic cells produce osteoid [22]. In both people and dogs, OSA is characterized by a highly pleomorphic and heterogeneous microscopic appearance, and it is divided into several histologic subtypes similar in both species (Table 1) $[22,23]$. Commonly, these subtypes are typically mixed in the same tumour, which questions the significance of histologic tumour classification for prognostic purposes. Indeed, histologic subtype could not be demonstrated to influence biological

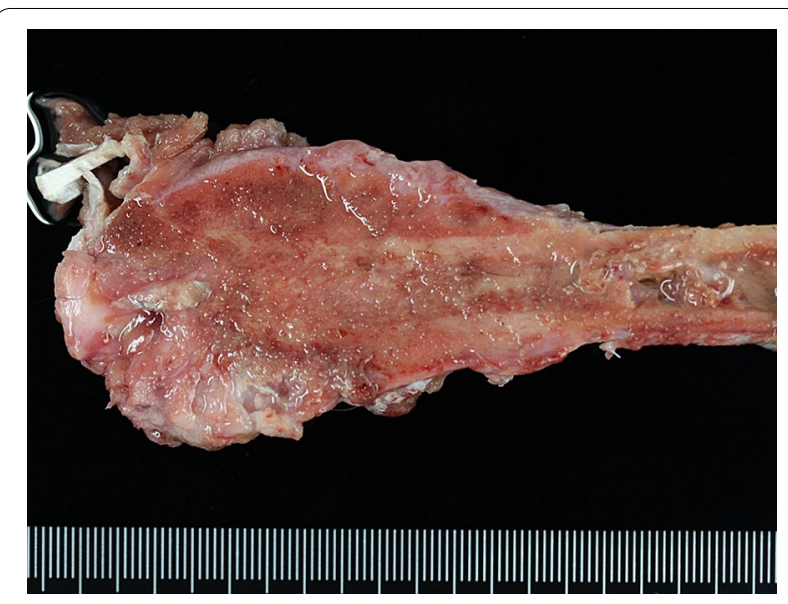

Fig. 1 Femoral osteosarcoma. Greyhound, 7 years and 7 months old. Dense sclerotic neoplastic proliferation with hard consistency at the level of the proximal metaphysis. The tumour infiltrates the medullary cavity and transgresses the cortical bone 
Table 1 Histologic subtypes of human and canine osteosarcoma

\begin{tabular}{|c|c|c|}
\hline Species & Canine $^{a}$ & Human $^{\mathbf{b}}$ \\
\hline \multirow[t]{13}{*}{ Subtypes } & A. Central & Osteosarcoma \\
\hline & Osteosarcoma & $\begin{array}{l}\text { Low-grade central osteo- } \\
\text { sarcoma }\end{array}$ \\
\hline & a. Poorly differentiated & Conventional \\
\hline & b. Osteoblastic & Chondroblastic \\
\hline & Nonproductive & Fibroblastic \\
\hline & Productive & Osteoblastic \\
\hline & c. Chondroblastic & Secondary \\
\hline & d. Fibroblastic & Telangiectatic \\
\hline & e. Telangiectatic & Small cell \\
\hline & f. Giant cell type & Parosteal \\
\hline & B. Peripheral & Periosteal \\
\hline & 1. Periosteal osteosarcoma & High grade surface \\
\hline & 2. Parosteal osteosarcoma & \\
\hline
\end{tabular}

${ }^{a}$ Based on World Health Organization (WHO) International Histological Classification of Tumors of Domestic Animals [23]

${ }^{b}$ Based on WHO Classification of Tumours of Bone [22]

tumour behavior in dogs [24] and is controversially discussed in human literature. The most common subtype is the osteoblastic form in both people and dogs (Fig. 2) $[21,25,26]$. Furthermore, OSAs are classified on tumour grade, which is based on microscopic features such as cellular pleomorphism, mitotic index, tumour matrix and degree of necrosis [25-27]. The vast majority of canine and human OSAs are high grade tumours [21, 26, 28]. Regarding the prognostic effect of OSA grading, the veterinary literature remains divided [26, 29, 30], whereas it is considered important and relevant for prognosis in human medicine [27].

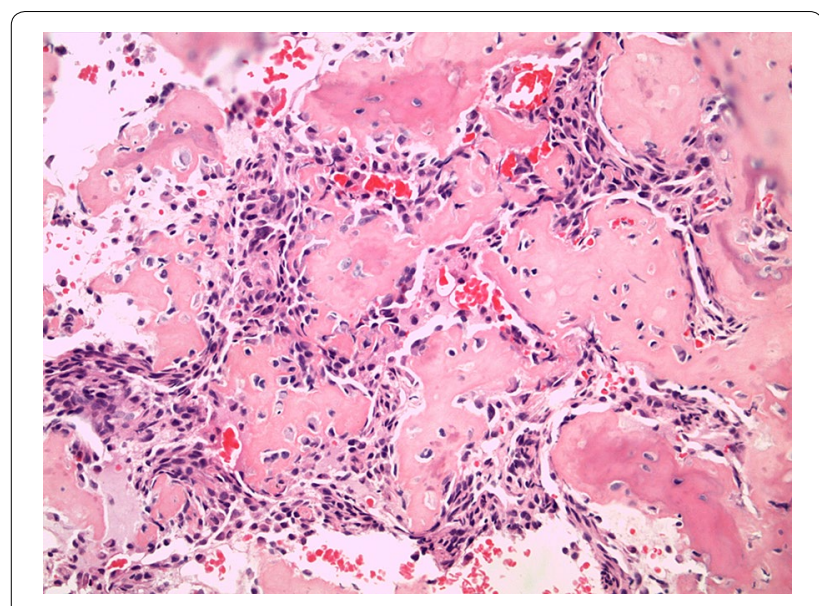

Fig. 2 Microphotograph of a productive osteoblastic osteosarcoma. Abundant accumulation of extracellular lakes of osteoid between malignant osteoblasts. Haematoxylin and eosin stain. Obj. 20x
The vast majority of OSAs in both dogs and humans arise from within bones, particularly in the metaphyseal regions of long bones [22, 23] but can also originate on the surface of the bone or be extra-osseous [21]. In both humans and large dogs, OSA has a clear preference for the appendicular skeleton (up to $80 \%$ in dogs and $90 \%$ in humans) over the axial skeleton, with different bone percentages of involvement associated to the main weight bearing regions in each species. In people, $\sim 50 \%$ of cases occur in the region of the knee (distal femur > proximal tibia followed by proximal humerus in approximately $25 \%$ of cases), in dogs the forelimbs are affected twice as often as the hind limbs (mainly distal radius and proximal humerus followed by distal and proximal femur and distal tibia) [31].

\section{Treatment of osteosarcoma in humans and dogs}

In both humans and dogs, treatment for OSA involves surgery to remove primary tumours and on occasion distant metastasis, combined with neoadjuvant and/or adjuvant chemotherapy [32,33]. Surgery involves either amputation of the limb or limb salvage/sparing procedures [34, 35]. Limb salvage is most frequently performed on patients with lower grade tumours and has been associated with similar outcomes to conventional approaches using amputation [35]. The proposed advantage of limb salvage surgery over amputation is that these patients have a better return-to-function and consequently quality-of-life than those undergoing amputation [36]. A recent meta-analysis supported this benefit in addition to a lower incidence of metastasis with limb salvage [37]. Similar advantages have yet to be reported in dogs undergoing limb salvage, perhaps suggesting poor cross-species efficacy. Canine reports suggest a similar metastatic frequency and survival time with limb salvage compared with the more conventional approach of amputation and adjuvant chemotherapy [38]. The failure to identify a significant difference in the outcomes in dogs compared with humans may be related to fewer numbers of dogs undergoing limb salvage procedures and therefore a more limited experience with the procedure. It is also possible that differences in case selection between humans and dogs impacts on outcome, in dogs clearly this may be the result of both patient factors and owner factors. Until a greater number of cases appear in the canine literature, the reason for the differences in outcomes remains unclear. Of note however from the canine literature on limb salvage, is that post-operative infections are associated with increased survival times [39-42]. The mechanism responsible for this prolonged survival and disease-free interval has yet to be elucidated, but is hypothesised to be due to up-regulation of antitumor immunity [39]. This is phenomenon is not unique 
to the dog and has also been reported in humans, with a similarly unclear aetiology [43, 44].

In human OSA, surgery with adjuvant chemotherapy remains the treatment of choice $[45,46]$. The standard adjuvant chemotherapeutic approach uses a combination of methotrexate, doxorubicin and cisplatin using either a high, moderate, or standard dose protocols [47-50]. This approach has remained relatively unaltered for many years. The inclusion of additional chemotherapeutics including ifosfamide has met with mixed results and meta-analyses have provided conflicting evidence as to whether this provides a clear benefit in all cases [51, 52]. Whilst a large number of protocol modifications and experimental therapies have been reported, these at present do not offer credible therapeutic alternatives to improve outcome in affected individuals [49]. However there is evidence suggesting six doses of carboplatin may be superior to alternating doxorubicin and carboplatin regimens [53]. In canine OSA adjuvant chemotherapy with either doxorubicin or the platinum-based compounds including cisplatin and carboplatin have been associated with increased survival times over amputation alone [54-57]. The relative merits of the individual chemotherapy drugs have been evaluated. Reports indicate no significant difference in disease free interval or survival times in those dogs receiving either post-operative doxorubicin or carboplatin or combinations thereof for OSA [32]. However, those dogs receiving carboplatin experienced fewer side-effects improving the quality of life during therapy, an important consideration for most owners. Combination protocols with doxorubicin and carboplatin have also been evaluated for their potential benefit in improving disease free interval and survival times [58]. This combination protocol has been associated with a greater degree of chemotherapy induced toxicity [59]. A recent prospective study comparing carboplatin with an alternating carboplatin-doxorubicin protocol showed no benefit of the combination in improving survival over carboplatin alone [53]. Other (retrospective) publications using this combination have failed to demonstrate a clear benefit over single-agent carboplatin [58, 59]. Limited publications exist evaluating the benefits of additional chemotherapeutic agents for canine OSA e.g. gemcitabine; none provide a clear improvement in outcome above the use of carboplatin [60].

The use of bisphosphonate therapy as an adjunct to standard approaches for treating OSA has received reasonable coverage in the literature. A wide variety of experimental data exists on their efficacy in vitro and in models of OSA [61-65]. There has however been equivocal clinical benefit from their use in both in vivo models and in naturally occurring disease [66-68]. Whilst their value in management of the primary disease is unclear, perhaps more compelling evidence exists for their role in managing metastatic disease [63,69-71]. This is a very important feature in managing OSA, given the importance of metastatic disease in overall mortality.

More recent reports on the use of immunotherapy based on an attenuated recombinant Listeria monocyotogenes expressing a chimeric HERS/neu fusion protein have shown some encouraging results [72]. Dogs having undergone surgery (with amputation or limb salvage) with post-operative chemotherapy with four doses of carboplatin were enrolled in this study. In these dogs, 3 weeks after completion of their chemotherapy protocol they received the immunotherapy agent. There was an overall increase in survival time and reduction in the incidence of metastasis compared with historic controls. Newer therapeutic treatments including immunotherapies are also being investigated and developed in people given the failure to improve the outcome of human patients significantly in the past 30 years [73-75].

Given the failure to significantly improve the treatment approach and therefore outcome of OSA in humans over the past 3 decades $[76,77]$ and in dogs over the same period [78-80], novel approaches are clearly required. One particular area of medicine that may provide improved treatment approaches for OSA focuses on the field of pharmacogenomics. Here specific pharmacogenetic biomarkers and targets can provide a personalised approach to therapy for OSA [81, 82]. This approach whilst desirable remains in its infancy but clearly provides exciting potential for future management of OSA in both humans and dogs.

\section{Prognostic factors for osteosarcoma in humans and dogs}

Key factors affecting treatment outcome are diagnostic and prognostic tools. Typical OSA disease progression consists of a primary tumour, usually originating within the medullary cavity, which grows, proliferates, and invades, and left unchecked frequently metastasises to the lungs [83]. Prognosis for individuals with metastatic tumours is much poorer than for individuals with only primary tumours. The 5-year-event-free-survival for humans with metastatic tumours at diagnosis reported to be $27.4 \%$, while individuals with no metastases at diagnosis the 5 -year-event-free-survival is $\sim 70 \%[15,83]$. The prognosis for canine OSA is poor with 1 year survival rates following diagnosis and treatment typically less than 45\% [84-86]. Of those dogs surviving beyond 1 year, $\sim 54 \%$ will develop metastatic disease with a median survival time of 243 days [40]. In dogs with evidence for metastatic disease at the time of diagnosis, the median survival time is 76 days [23]. There is gathering evidence in some cases (although limited by study numbers) that 
in addition to the understanding that certain breeds are predisposed to developing OSA, there are also specific genetic differences within the tumours encountered in certain breeds which may have prognostic significance $[87,88]$.

A number of factors have been suggested to have prognostic significance in canine OSA. Bodyweight and tumour location have been suggested to be of particular importance and are readily available parameters for all patients. Dogs with lower body weight have a longer survival time $[39,89,90]$ and dogs with proximal humeral tumours experience a shorter survival time [91]. Serum biomarkers have also been evaluated, such markers are clearly desirable particularly if routinely measured as this helps clinicians to begin discussions around prognosis with clients without recourse to advanced diagnostics. Increased serum alkaline phosphatase activity in dogs has been associated with a shorter disease free interval and survival time [92]. Histological grading is relevant for prognosis in human medicine [27], but remains controversial in dogs $[26,29,30]$. A recent meta-analysis in dogs has suggested that ALP and a proximal humeral location are significant negative prognostic factors. The importance of other factors was difficult to determine in this meta-analysis due to limited numbers of dogs and studies in which these had been reviewed [91]. In humans, the extent of any histological response to preoperative chemotherapy has significant predictive value for both local and distant disease control [48, 77]. A similar effect has not been reported in dogs, this may be due to pre-operative chemotherapy not being part of routine treatment for canine OSA. In both humans and dogs molecular and genetic factors have also been identified as having potential prognostic significance. Many of these have been identified in OSA cell lines and therefore their clinical significance needs clarifying, however a number of cell lines have shown similarities between human and canine OSA, these therefore represent a very valuable evaluation tool [93]. Some of the factors observed in cell lines include HER-2 and PTEN, which have also been identified in some tissue samples [31]. The expression of matrix metalloproteases have also been demonstrated in some tissue samples (MMPs 2 and 9), however the clinical and prognostic significance of these is unclear. In humans, the literature often has conflicting data on the significance of particular markers. For example, the human epidermal growth factor 2 oncogene (HER-2) has been suggested in some reports to have prognostic significance, though further study is required to definitively confirm this [94-96]. Epidermal growth factor has been evaluated in dogs, whilst expressed in primary and metastatic tumour cells, it has not been shown to be an effective prognostic marker clinically [97]. Vascular endothelial growth factor A (VEGFA) has also been implicated in prognosis and over-expression has been associated with shorter survival times in humans [98]. However, at present the actual value of VEGFA in prognostication remains to be clarified [98, 99]. In humans p53 has been shown to be an effective prognostic marker and upregulated p53 is associated with a shorter survival time [100]. This has also been associated with prognosis canine OSA [101]. Strong expression of CXCL-12 is also associated with a more favourable outcome in humans with OSA [96]. The significance of CXCL-12 expression has yet to be investigated in dogs. MicroRNA transcripts have also been investigated for their prognostic significance. It would seem that down-regulation of $14 \mathrm{q} 32$ miRNA expression is a conserved mechanism in both human and canine OSA samples and influences tumour behaviour [102]. One particularly promising molecule however is ezrin, a membrane cytoskeleton linking molecule. This has been associated with a shorted survival time in both humans and dogs with OSA [103-106]. In addition to overall prognosis, a number of factors have been implicated in the development of metastatic disease. Given that local disease control is not the major life-limiting aspect to both canine and human OSA, identifying factors affecting metastasis are crucial. A number of markers have been identified in humans including Hes4 [107] and in canine OSA the proto-oncogene c-Met has been implicated in lymphatic spread [108].

\section{Epidemiology and genetics of osteosarcoma in humans}

Some cases of human OSA are associated with heritable cancer syndromes, and the genetic bases of these have been established [109-111]. Most instances of OSA, however are not associated with heritable cancer syndromes and there have only been two heritable genetic loci identified, but there are some risk factors associated with OSA development including growth, puberty, sex, and race $[15,112,113]$. Evidence that growth plays a part in the development of OSA comes from the age of onset frequently coinciding with rapid bone growth during puberty, tumour sites most frequently at the end of bones where active growth occurs, and people affected by OSA are on average taller than the unaffected population [15, 112]. There is a difference between sexes in the development of OSA with males more commonly affected than females, and there is some evidence of variation in the incidence rate between races in the USA $[15,112]$. Although OSA itself does not appear to be directly heritable in most instances, there are heritable components to the risk factors [114].

There have been somatic mutations in tumour suppressor genes identified in individuals with heritable 
cancer syndromes, and there have been mutations identified in OSA tumours compared to non-tumours [109, 115-117]. There have, however, only been two somatic genetic mutations associated with OSA specifically [113]. This lack of identified somatic genetic associations is not surprising based on the lack of heritability observed in human OSA. Despite the lack of heritability and somatic genetic mutations identified there have been over 900 genes associated with human OSA [118]. These genes have been associated with OSA due to either differences in expression between tumour and non-tumour tissue, or due to mutations that have arisen in the tumour tissue compared to the non-tumour tissue [119-121]. Mutations in OSA tumour tissue, but not non-tumour tissue, and differences in gene expression between tumour and non-tumour tissue could be either the cause of the tumour or a result of the tumour. A possible cause of both differences in expression between tumour and non-tumour tissue, and mutations in tumour but not non-tumour tissue, is genomic and chromosomal instability [122, 123]. Genomic and chromosomal instability is a reported factor in many types of cancer progression $[122,123]$. OSA has been shown to display chromosomal instability associated with mutations in the TP53 gene [124]. A consequence of this chromosomal instability is aneuploidy, which can lead to the overexpression of some genes within malignant cells, disrupting normal cell processes [125]. Although mutations in TP53 appear to be associated with chromosomal instability, the gene itself does not seem to be subsequently over expressed following aneuploidy [124, 125].

\section{Epidemiology and genetics of osteosarcoma in dogs}

As outlined above, canine OSA is more common than human OSA [11, 12, 16]. Despite this there are similar risk factors associated with the development of OSA in dogs as in people, including growth and sex $[16,126]$. In addition, OSA in dogs is also influenced by breed and neutering status $[16,126]$. Large dogs constitute the majority of OSA cases [16, 94]. Similarly, people with OSA are commonly taller than average [112]. In the canine population, as with the human population, there also appears to be a sex disparity, with males more likely to develop OSA than females $[12,16]$. Neutering status, although not relevant in the human context, appears to contribute to OSA risk where neutered dogs are more likely to develop OSA than non-neutered dogs [126]. This, combined with the association with puberty, suggests a complex role for sex hormone signalling in OSA risk. In contrast to human OSA, canine OSA appears to be heritable, with some breeds appearing to be predisposed to developing OSA compared to others [16, 127].
Interestingly of the 15 breeds with the highest reported incidence of OSA 12 are within a clear clade on the canine phylogeny $[16,128]$. This relationship between affected breeds could indicate a potential common genetic origin of canine OSA across breeds, however the clade is large and contains many breeds that are not highly affected by OSA, thus this seems less likely [128].

Four breeds of dog that have a high incidence of OSA are the Rottweiler, Greyhound, Deerhound and Irish Wolfhound. The Irish Wolfhound, the largest breed, has the highest prevalence of OSA within the insured Swedish dog population once numbers within the population are taken into account [16]. It also has one of the lower median ages of onset at 6.6 years, only the greyhound has a lower median age of onset at 6.2 years [16]. Greyhounds are recognised to frequently develop OSA-accounting for around $25 \%$ of mortality in some cohorts $[129,130]$. Although The Irish Wolfhound history includes a period when they were close to extinction [131]. In the process of conserving the breed the few remaining Irish Wolfhounds were crossed with Great Danes, Deerhounds, Borzois, and Mastiffs [131, 132]. This out-crossing will have introduced some genetic diversity, but to retain the Irish Wolfhound phenotype a large amount of inbreeding will have been required, therefore as with most modern breeds, genetic diversity is low within the breed [133]. Importantly for the Irish Wolfhound breed both Great Danes and Deerhounds have a high prevalence of OSA, and these were two breeds used to help rescue Irish Wolfhounds from extinction [16, 127, 131]. Combined with inbreeding, the use of two breeds predisposed to developing OSA could have led to Irish Wolfhounds acquiring OSA predisposition genes from both breeds. The Deerhound, a hunting dog, with references as far back as the third century; was split into various strains in the early nineteenth century, which is likely to have had an effect on genetic diversity. The Rottweiler is also a large breed of $\operatorname{dog}$ and within the insured Swedish dog population they have the 5th highest incidence ranking (after correction for actual numbers of dogs) for OSA with a median age of onset of 7.9 years [16]. The Rottweiler originated in Germany being used for guarding, droving, and as a draught dog [134]. Following the creation of breed standards in the 1930s, when the breed was registered with the UK and American Kennel Clubs it is likely that Rottweilers have exclusively been mated with other Rottweilers leading to a closed gene pool within the pedigree Rottweiler population $[134,135]$.

There have been 34 genetic loci associated with canine OSA across four breeds [136, 137]. One study identified 33 loci as associated with canine OSA across three breeds [136] and another identified a single locus associated with OSA in Deerhounds [137]. None of the loci 
were consistently associated across breeds, further suggesting that there may be a difference between breeds in the genetic predisposition to developing canine OSA $[136,137]$. There have been 4 loci associated with the development of OSA in Irish Wolfhounds [136]. In Rottweilers 15 loci were associated with the development of OSA [136]. Deerhounds also have a high prevalence of OSA with an incidence rate of $15 \%$ and a heritability value of $0.69[126,127]$. Those Deerhounds carrying putative high-risk dominant allele are considered to have a $>75 \%$ risk of developing OSA compared with those not carrying the allele. This has been mapped to CFA34 [137]. Unusually, in this breed, females appear to have an increased risk of developing OSA; this is not influenced by the neuter status [127]. Genetic analysis of Greyhounds has shown 14 inherited risk loci, the strongest in this breed was located $150 \mathrm{~kb}$ upstream of the tumour suppressor genes CDKN2A/B [136]. Interestingly the risk of developing OSA seems not to be a general feature of derivative breeds such as Whippets. Despite close clustering of molecular microsatellite markers, Whippets rarely suffer from OSA [138]. This raises the question of whether genetic factors alone account for the incidence of OSA in this breed. The influence of IGF-1 on size variation in dogs may have an influence in this regard, given the possible association with the development of canine OSA [139].

Currently none of the genetic variants identified as associated with canine OSA have been mechanistically verified. Verification of the mode of action could lead to the identification of novel therapeutic targets, and if these loci can be shown to consistently predict an increased risk of OSA, the number of affected individuals could be reduced. Breeders could genotype prospective sires and dams prior to mating and choose parents to reduce the risk of offspring having multiple deleterious OSA alleles in conjunction with minimising the epidemiological factors. In addition to the 34 genetic loci identified as associated with canine OSA, there have been genes identified as differentially expressed in canine OSA compared to non-tumour tissue that have implications for growth and metastasis, and are potential drug targets [140-143]. These genes have been identified utilising canine OSA tumour tissue, and canine OSA cell lines. There has also been variation in the expression of genes within tumours associated with survival time in canine OSA [97, 144-146].

\section{Conclusions}

There are several dog breeds that appear to have a genetic predisposition to OSA for which no OSA associated loci have been identified, these breeds could benefit from the identification of OSA predisposition loci. Additional work is required to confirm the effect of the genetic loci identified as associated with canine OSA, and account for the variation observed in the development of disease. This is also the case with humans, therefore comparing the two species may provide valuable insights into disease origins and progression, given the many similarities between the tumour in both species. Further work is also required to establish improved treatment regimens for individuals that develop disease, the identification of particular genetic pathways that are altered in OSA tumour tissue compared to non-tumour tissue could facilitate this. Any genetic loci identified as associated with canine OSA have the potential to be examined for an association with human OSA, and any treatments shown to be effective in either species could be applied to the other.

\section{Abbreviations}

HER-2: human epidermal growth factor 2 oncogene; OSA: osteosarcoma; SEER: surveillance, epidemiology, evidence and end results; VEGFA: vascular endothelial growth factor A; WHO: World Health Organisation.

\section{Authors' contributions}

All authors contributed towards the writing. CSR and NPM fostered the idea of the review and coordinated the writing process. CSR, SS and NPM drafted the background, and sections on epidemiology and genetics, MD and SS drafted the section on clinical treatment and prognostics, SDB and LGR drafted the section on histology. All authors read and approved the final manuscript.

\section{Authors' information}

SS (BSC, MSc, PhD) under took her PhD in osteosarcoma genomics and epidemiology, under the supervision of CSR and NPM. MD is a Clinical Associate Professor in Small Animal Internal Medicine (MA, VetMB, PhD, CertSAM, DipECVIM-CA, MRCVS), European Veterinary Specialist in Small Animal Internal Medicine and RCVS Recognised Specialist in Small Animal Internal Medicine. $\mathrm{SdB}$ is a Clinical Assistant Professor in Veterinary Pathology (DVM, Dr.med. vet., ECVP Diplomate) who has been active in comparative (primarily canine and human) cancer research since 2004. LGR is a Clinical Assistant Professor in Veterinary Pathology (BSC, DVM, PhD, ECVP Diplomate). NPM is an Associate Professor of Cancer Biology [BSC (Hons) PhD]. He is a Fellow of the Royal College of Pathology with more than 15 years' experience in translational cancer research and genomics. CSR is an Assistant Professor in Anatomy and Developmental Genetics [BSc (Hons), MSc, MMedSci, PhD, FAS], Fellow of the Anatomical Society and the Galton Institute with over 15 years research experience in histology and genomics.

\section{Author details \\ ${ }^{1}$ Faculty of Medicine and Health Sciences, School of Veterinary Medicine and Science, The University of Nottingham, Sutton Bonington Campus, Loughborough LE12 5RD, UK. ${ }^{2}$ Department of Pharmacology, Weill Cornell Medicine, 1300 York Avenue, New York, NY 10065, USA.}

\section{Acknowledgements}

We would like to thank Professor Malcolm Cobb, School of Veterinary Medicine and Science, University of Nottingham for his insight and expertise.

\section{Competing interests}

The authors declare that they have no competing interests.

\section{Funding}

The authors declare that they have no competing interests. This work was supported by the Biotechnology and Biological Sciences Research Council (Grant Number BB/J014508/1), by generous funding to Nigel P. Mongan and Catrin S. Rutland from the BBSRC University of Nottingham Doctoral Training Programme. The funders did not participate in any aspect of the manuscript. 


\section{Publisher's Note}

Springer Nature remains neutral with regard to jurisdictional claims in published maps and institutional affiliations.

Received: 24 March 2017 Accepted: 18 October 2017

Published online: 24 October 2017

\section{References}

1. Siegel RL, Miller KD, Jemal A. Cancer statistics, 2015. CA Cancer J Clin. 2015;65:5-29.

2. World Health Organisation. Noncommunicable diseases country profiles 2014. http://apps.who.int/iris/bitstr eam/10665/128038/1/9789241507509_eng.pdf (2014). Accessed 28 May 2017.

3. Bonnett B, Egenvall A, Hedhammar A, Olson P. Mortality in over 350,000 insured Swedish dogs from 1995-2000: I. Breed-, gender-, age- and cause-specific rates. Acta Vet Scand. 2005;46:105-20.

4. DeVita VT, Chu E. A history of cancer chemotherapy. Cancer Res. 2008:68:8643-53.

5. Grüntzig K, Graf R, Hässig M, Welle M, Meier D, Lott G, Erni D, Schenker NS, Guscetti F, Boo G, et al. The swiss canine cancer registry: a retrospective study on the occurrence of tumours in dogs in Switzerland from 1955 to 2008. J Comp Pathol. 2015;152:161-71.

6. Ranieri G, Gadaleta CD, Patruno R, Zizzo N, Daidone MG, Hansson MG, Paradiso A, Ribatti D. A model of study for human cancer: spontaneous occurring tumors in dogs. Biological features and translation for new anticancer therapies. Crit Rev Oncol Hematol. 2013;88:187-97.

7. Schneider R. Comparison of age, sex, and incidence rates in human and canine breast cancer. Cancer. 1970;26:419-26.

8. Pinho SS, Carvalho S, Cabral J, Reis CA, Gärtner F. Canine tumors: a spontaneous animal model of human carcinogenesis. Transl Res. 2012;159:165-72.

9. Page R, Baneux P, Vail D, Duda L, Olson P, Anestidou L, Dybdal N, Golab G, Shelton W, Salgaller M, Hardy C. Conduct, oversight, and ethical considerations of clinical trials in companion animals with cancer: report of a workshop on best practice recommendations. J Vet Intern Med. 2016;30:527-35

10. Forman D, Bray F, Brewster DH, Gombe Mbalawa C, Kohler B, Piñeros MSF, Swaminathan R, Ferlay J. Cancer incidence in five continents, vol. X. IARC Scientific Publication No. 164. Lyon: International Agency for Research on Cancer; 2014

11. Parkin DM, Ferlay J, Curado M-P, Bray F, Edwards B, Shin H-R, Forman D. Fifty years of cancer incidence: CI5 I-IX. Int J Cancer. 2010;127:2918-27.

12. Mirabello L, Troisi RJ, Savage SA. International osteosarcoma incidence patterns in children and adolescents, middle ages and elderly persons. Int J Cancer. 2009;125:229-34.

13. Siegel R, Naishadham D, Jemal A. Cancer statistics, 2013. CA Cancer J Clin. 2013;63:11-30

14. Dorfman HD, Czerniak B. Bone cancers. Cancer. 1995;75:203-10.

15. Mirabello L, Troisi RJ, Savage SA. Osteosarcoma incidence and survival rates from 1973 to 2004: data from the surveillance, epidemiology, and end results program. Cancer. 2009;115:1531-43.

16. Egenvall A, Nødtvedt A, von Euler H. Bone tumors in a population of 400000 insured Swedish dogs up to 10 y of age: incidence and survival. Can J Vet Res. 2007;71:292-9.

17. Jemal A, Tiwari RC, Murray T, Ghafoor A, Samuels A, Ward E, Feuer EJ, Thun MJ. Cancer statistics, 2004. CA Cancer J Clin. 2004;54:8-29.

18. Anfinsen KP, Grotmol T, Bruland OS, Jonasdottir TJ. Breed-specific incidence rates of canine primary bone tumors-a population based survey of dogs in norway. Can J Vet Res. 2011;75:209-15.

19. Sapierzynski R, Czopowicz M. The animal-dependent risk factors in canine osteosarcomas. Pol J Vet Sci. 2017;20:293-8.

20. Souhami R, Tobias J, editors. Bone and soft-tissue sarcomas. In: Cancer and its management. Chichester: Blackwell Publishing Ltd; 2005. p. 386-404.

21. Klein MJ, Siegal GP. Osteosarcoma: anatomic and histologic variants. Am J Clin Pathol. 2006;125:555-81.
22. Fletcher CDM, Bridge JA, Hogendoorn PCW, Mertens F. Who classification of tumours of soft tissue and bone. 4th ed. Geneva: WHO Press; 2013.

23. Slayter MV, Boosinger TR, Pool RR, Dammrich K, Misdrop W, Larsen S, World Health Organization. International histologic classification of tumors of domestic animals, histological classification of bone and joint tumors of domestic animals. Washington, DC: Armed Forces Institute of Pathology American Registry of Pathology; 1994

24. Nagamine E, Hirayama K, Matsuda K, Okamoto M, Ohmachi T, Kadosawa T, Taniyama H. Diversity of histologic patterns and expression of cytoskeletal proteins in canine skeletal osteosarcoma. Vet Pathol. 2015;52:977-84.

25. Fenger JM, London CA, Kisseberth WC. Canine osteosarcoma: a naturally occurring disease to inform pediatric oncology. ILAR J. 2014;55:69-85

26. Loukopoulos P, Robinson WF. Clinicopathological relevance of tumour grading in canine osteosarcoma. J Comp Pathol. 2007;136:65-73.

27. Righi A, Paioli A, Dei Tos AP, Gambarotti M, Palmerini E, Cesari M, Marchesi E, Donati DM, Picci P, Ferrari S. High-grade focal areas in low-grade central osteosarcoma: high-grade or still low-grade osteosarcoma? Clin Sarcoma Res. 2015;5:23.

28. Withrow SJ, Wilkins RM. Cross talk from pets to people: translational osteosarcoma treatments. ILAR J. 2010;51:208-13.

29. Kirpensteijn J, Kik M, Rutteman GR, Teske E. Prognostic significance of a new histologic grading system for canine osteosarcoma. Vet Pathol. 2002;39:240-6.

30. Kruse MA, Holmes ES, Balko JA, Fernandez S, Brown DC, Goldschmidt $\mathrm{MH}$. Evaluation of clinical and histopathologic prognostic factors for survival in canine osteosarcoma of the extracranial flat and irregular bones. Vet Pathol. 2013;50:704-8.

31. Morello E, Martano M, Buracco P. Biology, diagnosis and treatment of canine appendicular osteosarcoma: similarities and differences with human osteosarcoma. Vet J. 2011:189:268-77.

32. Selmic LE, Burton JH, Thamm DH, Withrow SJ, Lana SE. Comparison of carboplatin and doxorubicin-based chemotherapy protocols in 470 dogs after amputation for treatment of appendicular osteosarcoma. J Vet Intern Med. 2014;28:554-63.

33. Ta HT, Dass CR, Choong PFM, Dunstan DE. Osteosarcoma treatment: state of the art. Cancer Metastasis Rev. 2009;28:247-63.

34. Liptak JM, Dernell WS, Ehrhart N, Lafferty MH, Monteith GJ, Withrow SJ. Cortical allograft and endoprosthesis for limb-sparing surgery in dogs with distal radial osteosarcoma: a prospective clinical comparison of two different limb-sparing techniques. Vet Surg. 2006;35:518-33.

35. Reddy KIA, Wafa H, Gaston CL, Grimer RJ, Abudu AT, Jeys LM, Carter SR, Tillman RM. Does amputation offer any survival benefit over limb salvage in osteosarcoma patients with poor chemonecrosis and close margins? Bone Joint J. 2015;97(B):115-20.

36. Mavrogenis A, Abati C, Romagnoli C, Ruggieri P. Similar survival but better function for patients after limb salvage versus amputation for distal tibia osteosarcoma. Clin Orthop Relat Res. 2012;470:1735-48.

37. Li X, Zhang Y, Wan S, Li H, Li D, Xia J, Yuan Z, Ren M, Yu S, Li S, et al. A comparative study between limb-salvage and amputation for treating osteosarcoma. J Bone Oncol. 2016:5:15-21.

38. Mitchell KE, Boston SE, Kung M, Dry S, Straw RC, Ehrhart NP, Ryan SD. Outcomes of limb-sparing surgery using two generations of metal endoprosthesis in 45 dogs with distal radial osteosarcoma. A veterinary society of surgical oncology retrospective study. Vet Surg. 2016:45:36-43.

39. Lascelles BD, Dernell WS, Correa MT, Lafferty M, Devitt CM, Kuntz CA, Straw RC, Withrow SJ. Improved survival associated with postoperative wound infection in dogs treated with limb-salvage surgery for osteosarcoma. Ann Surg Oncol. 2005;12:1073-83.

40. Culp WT, Olea-Popelka F, Sefton J, Aldridge CF, Withrow SJ, Lafferty MH, Rebhun RB, Kent MS, Ehrhart N. Evaluation of outcome and prognostic factors for dogs living greater than one year after diagnosis of osteosarcoma: 90 cases (1997-2008). J Am Vet Med Assoc. 2014:245:1141-6.

41. Sottnik JL, U'Ren LW, Thamm DH, Withrow SJ, Dow SW. Chronic bacterial osteomyelitis suppression of tumor growth requires innate immune responses. Cancer Immunol Immunother. 2010;59:367-78. 
42. Seo K, Holt R, Jung YS, Rodriguez CO Jr, Chen X, Rebhun RB. Fluoroquinolone-mediated inhibition of cell growth, S-G2/M cell cycle arrest, and apoptosis in canine osteosarcoma cell lines. PLoS ONE. 2012;7:e42960.

43. Jeys LM, Grimer RJ, Carter SR, Tillman RM, Abudu A. Post operative infection and increased survival in osteosarcoma patients: are they associated? Ann Surg Oncol. 2007;14:2887-95.

44. Chen YU, Xu SF, Xu M, Yu XC. Postoperative infection and survival in osteosarcoma patients: reconsideration of immunotherapy for osteosarcoma. Mol Clin Oncol. 2015;3:495-500.

45. Anderson ME. Update on survival in osteosarcoma. Orthop Clin North Am. 2016:47:283-92.

46. Luetke A, Meyers PA, Lewis I, Juergens H. Osteosarcoma treatmentwhere do we stand? A state of the art review. Cancer Treat Rev. 2014;40:523-32

47. Winkler K, Bielack SS, Delling G, Jurgens H, Kotz R, Salzer-Kuntschik M. Treatment of osteosarcoma: experience of the cooperative osteosarcoma study group (COSS). Cancer Treat Res. 1993;62:269-77.

48. Zhang FY, Tang W, Zhang ZZ, Huang JC, Zhang SX, Zhao XC. Systematic review of high-dose and standard-dose chemotherapies in the treatment of primary well-differentiated osteosarcoma. Tumour Biol. 2014;35:10419-27.

49. Ferrari S, Serra M. An update on chemotherapy for osteosarcoma. Expert Opin Pharmacother. 2015;16:2727-36.

50. Wang WG, Wan C, Liao GJ. The efficacy of high-dose versus moderatedose chemotherapy in treating osteosarcoma: a systematic review and meta-analysis. Int J Clin Exp Med. 2015;8:15967-74.

51. Fan XL, Cai GP, Zhu LL, Ding GM. Efficacy and safety of ifosfamide-based chemotherapy for osteosarcoma: a meta-analysis. Drug Des Dev Ther. 2015;9:5925-32

52. Su W, Lai Z, Wu F, Lin Y, Mo Y, Yang Z, Wu J. Clinical efficacy of preoperative chemotherapy with or without ifosfamide in patients with osteosarcoma of the extremity: meta-analysis of randomized controlled trials. Med Oncol. 2015:32:481.

53. Skorupski KA, Uhl JM, Szivek A, Allstadt Frazier SD, Rebhun RB, Rodriguez CO Jr. Carboplatin versus alternating carboplatin and doxorubicin for the adjuvant treatment of canine appendicular osteosarcoma: a randomized, phase iii trial. Vet Comp Oncol. 2016;14:81-7.

54. Berg J. Canine osteosarcoma: amputation and chemotherapy. Vet Clin North Am Small Anim Pract. 1996;26:111-21.

55. Phillips B, Powers BE, Dernell WS, Straw RC, Khanna C, Hogge GS, Vail DM. Use of single-agent carboplatin as adjuvant or neoadjuvant therapy in conjunction with amputation for appendicular osteosarcoma in dogs. J Am Anim Hosp Assoc. 2009;45:33-8.

56. Saam DE, Liptak JM, Stalker MJ, Chun R. Predictors of outcome in dogs treated with adjuvant carboplatin for appendicular osteosarcoma: 65 cases (1996-2006). J Am Vet Med Assoc. 2011;238:195-206.

57. Alvarez FJ, Kisseberth W, Hosoya K, Lara-Garcia A, Kosarek C, Murahari S, Au JL, Wientjes MG, Couto J, Couto G. Postoperative adjuvant combination therapy with doxorubicin and noncytotoxic suramin in dogs with appendicular osteosarcoma. J Am Anim Hosp Assoc. 2014;50:12-8.

58. Kent MS, Strom A, London CA, Seguin B. Alternating carboplatin and doxorubicin as adjunctive chemotherapy to amputation or limb-sparing surgery in the treatment of appendicular osteosarcoma in dogs. J Vet Intern Med. 2004;18:540-4.

59. Bacon NJ, Ehrhart NP, Dernell WS, Lafferty M, Withrow SJ. Use of alternating administration of carboplatin and doxorubicin in dogs with microscopic metastases after amputation for appendicular osteosarcoma: 50 cases (1999-2006). J Am Vet Med Assoc. 2008;232:1504-10.

60. McMahon M, Mathie T, Stingle N, Romansik E, Vail D, London C. Adjuvant carboplatin and gemcitabine combination chemotherapy postamputation in canine appendicular osteosarcoma. J Vet Intern Med. 2011;25:511-7

61. Evdokiou A, Labrinidis A, Bouralexis S, Hay S, Findlay DM. Induction of cell death of human osteogenic sarcoma cells by zoledronic acid resembles anoikis. Bone. 2003;33:216-28.

62. Horie N, Murata H, Kimura S, Takeshita H, Sakabe T, Matsui T, Maekawa T, Kubo T, Fushiki S. Combined effects of a third-generation bisphosphonate, zoledronic acid with other anticancer agents against murine osteosarcoma. Br J Cancer. 2007;96:255-61.

63. Zekri J, Mansour M, Karim SM. The anti-tumour effects of zoledronic acid. J Bone Oncol. 2014;3:25-35.
64. Ohba T, Cates JM, Cole HA, Slosky DA, Haro H, Ichikawa J, Ando T, Schwartz HS, Schoenecker JG. Pleiotropic effects of bisphosphonates on osteosarcoma. Bone. 2014;63:110-20.

65. Wu CC, Huang YF, Hsieh CP, Chueh PJ, Chen YL. Combined use of zoledronic acid augments ursolic acid-induced apoptosis in human osteosarcoma cells through enhanced oxidative stress and autophagy. Molecules. 2016:21(12):1640.

66. Endo-Munoz L, Cumming A, Rickwood D, Wilson D, Cueva C, Ng C, Strutton G, Cassady AI, Evdokiou A, Sommerville S, et al. Loss of osteoclasts contributes to development of osteosarcoma pulmonary metastases. Cancer Res. 2010;70:7063-72.

67. Wolfe TD, Pillai SPS, Hildreth BE, Lanigan LG, Martin CK, Werbeck JL, Rosol TJ. Effect of zoledronic acid and amputation on bone invasion and lung metastasis of canine osteosarcoma in nude mice. Clin Exp Metastasis. 2011;28:377-89.

68. Piperno-Neumann S, Le Deley MC, Redini F, Pacquement H, MarecBerard P, Petit P, Brisse H, Lervat C, Gentet JC, Entz-Werle N, et al. Zoledronate in combination with chemotherapy and surgery to treat osteosarcoma (os2006): a randomised, multicentre, open-label, phase 3 trial. Lancet Oncol. 2016;17:1070-80.

69. Koto K, Horie N, Kimura S, Murata H, Sakabe T, Matsui T, Watanabe M, Adachi S, Maekawa T, Fushiki S, Kubo T. Clinically relevant dose of zoledronic acid inhibits spontaneous lung metastasis in a murine osteosarcoma model. Cancer Lett. 2009:274:271-8.

70. Conry RM, Rodriguez MG, Pressey JG. Zoledronic acid in metastatic osteosarcoma: encouraging progression free survival in four consecutive patients. Clin Sarcoma Res. 2016;6:6.

71. Byrum ML, Pondenis HC, Fredrickson RL, Wycislo KL, Fan TM. Downregulation of CXCR4 expression and functionality after zoledronate exposure in canine osteosarcoma. J Vet Intern Med. 2016;30:1187-96.

72. Mason NJ, Gnanandarajah JS, Engiles JB, Gray F, Laughlin D, GaurnierHausser A, Wallecha A, Huebner M, Paterson Y. Immunotherapy with a HER2-targeting listeria induces HER2-specific immunity and demonstrates potential therapeutic effects in a phase i trial in canine osteosarcoma. Clin Cancer Res. 2016;22:4380-90.

73. Bishop MW, Janeway KA, Gorlick R. Future directions in the treatment of osteosarcoma. Curr Opin Pediatr. 2016;28:26-33.

74. Wan J, Zhang X, Liu T. Strategies and developments of immunotherapies in osteosarcoma. Oncol Lett. 2016;11:511-20.

75. Botter SM, Neri D, Fuchs B. Recent advances in osteosarcoma. Curr Opin Pharmacol. 2014;16:15-23.

76. Murakami T, Igarashi K, Kawaguchi K, Kiyuna T, Zhang Y, Zhao M Hiroshima Y, Nelson SD, Dry SM, Li Y, et al. Tumor-targeting salmonella typhimurium A1-R regresses an osteosarcoma in a patient-derived xenograft model resistant to a molecular-targeting drug. Oncotarget. 2017:8:8035-42.

77. Bielack SS, Hecker-Nolting S, Blattmann C, Kager L. Advances in the management of osteosarcoma. F1000Research. 2016;5:2767.

78. Shapiro W, Fossum TW, Kitchell BE, Couto CG, Theilen GH. Use of cisplatin for treatment of appendicular osteo-sarcoma in dogs. J Am Vet Med Assoc. 1988;192:507-11.

79. Thompson JP, Fugent MJ. Evaluation of survival times after limb amputation, with and without subsequent administration of cisplatin, for treatment of appendicular osteosarcoma in dogs - 30 cases (1979-1990). J Am Vet Med Assoc. 1992;200:531-3.

80. MacEwen EG, Kurzman ID. Canine osteosarcoma: amputation and chemoimmunotherapy. Vet Clin North Am Small Anim Pract. 1996;26:123-33.

81. Serra M, Hattinger CM. The pharmacogenomics of osteosarcoma. Pharmacogenomics J. 2017;17:11-20.

82. Vos HI, Coenen MJ, Guchelaar HJ, Te Loo DM. The role of pharmacogenetics in the treatment of osteosarcoma. Drug Discov Today. 2016;21:1775-86

83. Bacci G, Rocca M, Salone M, Balladelli A, Ferrari S, Palmerini E, Forni C, Briccoli A. High grade osteosarcoma of the extremities with lung metastases at presentation: treatment with neoadjuvant chemotherapy and simultaneous resection of primary and metastatic lesions. J Surg Oncol. 2008;98:415-20.

84. Frimberger AE, Chan CM, Moore AS. Canine osteosarcoma treated by post-amputation sequential accelerated doxorubicin and carboplatin chemotherapy: 38 cases. J Am Anim Hosp Assoc. 2016;52:149-56. 
85. Moore AS, Dernell WS, Ogilvie GK, Kristal O, Elmslie R, Kitchell B, Susaneck S, Rosenthal R, Klein MK, Obradovoich J, et al. Doxorubicin and bay 12-9566 for the treatment of osteosarcoma in dogs: a randomized, double-blind, placebo-controlled study. J Vet Intern Med. 2007;21:783-90

86. Straw RC, Withrow SJ, Richter SL, Powers BE, Klein MK, Postorino NC, LaRue SM, Ogilvie GK, Vail DM, Morrison WB, et al. Amputation and cisplatin for treatment of canine osteosarcoma. J Vet Intern Med. 1991;5:205-10.

87. Thomas R, Wang HJ, Tsai PC, Langford CF, Fosmire SP, Jubala CM, Getzy DM, Cutter GR, Modiano JF, Breen M. Influence of genetic background on tumor karyotypes: evidence for breed-associated cytogenetic aberrations in canine appendicular osteosarcoma. Chromosome Res. 2009; 17:365-77.

88. Angstadt AY, Motsinger-Reif A, Thomas R, Kisseberth WC, Guillermo Couto C, Duval DL, Nielsen DM, Modiano JF, Breen M. Characterization of canine osteosarcoma by array comparative genomic hybridization and Rt-qPCR: signatures of genomic imbalance in canine osteosarcoma parallel the human counterpart. Gene Chromosome Cancer. 2011;50:859-74.

89. Bergman PJ, MacEwen EG, Kurzman ID, Henry CJ, Hammer AS, Knapp DW, Hale A, Kruth SA, Klein MK, Klausner J, et al. Amputation and carboplatin for treatment of dogs with osteosarcoma: 48 cases (1991 to 1993). J Vet Intern Med. 1996;10:76-81.

90. Amsellem PM, Selmic LE, Wypij JM, Bacon NJ, Culp WT, Ehrhart NP, Powers BE, Stryhn H, Farese JP. Appendicular osteosarcoma in small-breed dogs: 51 cases (1986-2011). J Am Vet Med Assoc. 2014;245:203-10.

91. Boerman I, Selvarajah GT, Nielen M, Kirpensteijn J. Prognostic factors in canine appendicular osteosarcoma - a meta-analysis. BMC Vet Res. 2012;8:56.

92. Garzotto CK, Berg J, Hoffmann WE, Rand WM. Prognostic significance of serum alkaline phosphatase activity in canine appendicular osteosarcoma. J Vet Intern Med. 2000;14:587-92.

93. Wilson H, Huelsmeyer M, Chun R, Young KM, Friedrichs K, Argyle DJ. Isolation and characterisation of cancer stem cells from canine osteosarcoma. Vet J. 2008;175:69-75.

94. Zhang Q, Liu F, Wang B, Li Z, Zhou D, Yang Q, Dong J, Li J. HER-2 expression in biopsy and surgical specimen on prognosis of osteosarcoma: a systematic review and meta-analysis of 16 studies. Medicine (Baltimore). 2016:95:e3661.

95. Gill J, Geller D, Gorlick R. HER-2 involvement in osteosarcoma. Adv Exp Med Biol. 2014:804:161-77.

96. Baumhoer D, Smida J, Specht K, Bink K, Quintanilla-Martinez L, Rosemann M, Siggelkow H, Nathrath WB, Atkinson MJ, Bielack S, et al. Aberrant expression of the human epidermal growth factor receptor 2 oncogene is not a common feature in osteosarcoma. Hum Pathol. 2011:42:859-66.

97. Selvarajah GT, Verheije MH, Kik M, Slob A, Rottier PJM, Mol JA, Kirpensteijn J. Expression of epidermal growth factor receptor in canine osteosarcoma: association with clinicopathological parameters and prognosis. Vet J. 2012;193:412-9.

98. Yu XW, Wu TY, Yi X, Ren WP, Zhou ZB, Sun YQ, Zhang CQ. Prognostic significance of VEGF expression in osteosarcoma: a meta-analysis. Tumour Biol. 2014;35:155-60.

99. Qu JT, Wang M, He HL, Tang Y, Ye XJ. The prognostic value of elevated vascular endothelial growth factor in patients with osteosarcoma: a meta-analysis and systemic review. J Cancer Res Clin Oncol. 2012;138:819-25

100. Fu HL, Shao L, Wang Q, Jia T, Li M, Yang DP. A systematic review of p53 as a biomarker of survival in patients with osteosarcoma. Tumour Biol. 2013;34:3817-21.

101. Kirpensteijn J, Kik M, Teske E, Rutteman GR. TP53 gene mutations in canine osteosarcoma. Vet Surg. 2008;37:454-60.

102. Sarver AL, Thayanithy V, Scott MC, Cleton-Jansen AM, Hogendoorn PC, Modiano JF, Subramanian S. Micrornas at the human 14q32 locus have prognostic significance in osteosarcoma. Orphanet J Rare Dis. 2013;8:7.

103. Jaroensong T, Endo Y, Lee SJ, Kamida A, Mochizuki M, Nishimura R, Sasaki N, Nakagawa T. Effects of transplantation sites on tumour growth, pulmonary metastasis and ezrin expression of canine osteosarcoma cell lines in nude mice. Vet Comp Oncol. 2012;10:274-82.
104. Ren L, Hong SH, Chen QR, Briggs J, Cassavaugh J, Srinivasan S, Lizardo MM, Mendoza A, Xia AY, Avadhani N, et al. Dysregulation of ezrin phosphorylation prevents metastasis and alters cellular metabolism in osteosarcoma. Cancer Res. 2012;72:1001-12.

105. Khanna C, Wan X, Bose S, Cassaday R, Olomu O, Mendoza A, Yeung C, Gorlick R, Hewitt SM, Helman LJ. The membrane-cytoskeleton linker ezrin is necessary for osteosarcoma metastasis. Nat Med. 2004;10:182-6.

106. Xu-Dong S, Zan S, Shui-er Z, Li-na T, Wen-xi Y, Feng L, Yang Y. Expression of ezrin correlates with lung metastasis in Chinese patients with osteosarcoma. Clin Invest Med. 2009;32:E180-8.

107. McManus M, Kleinerman E, Yang Y, Livingston JA, Mortus J, Rivera R, Zweidler-McKay P, Schadler K. Hes4: A potential prognostic biomarker for newly diagnosed patients with high-grade osteosarcoma. Pediatr Blood Cancer. 2016. doi:10.1002/pbc.26318.

108. Fieten H, Spee B, ljzer J, Kik MJ, Penning LC, Kirpensteijn J. Expression of hepatocyte growth factor and the proto-oncogenic receptor c-Met in canine osteosarcoma. Vet Pathol. 2009;46:869-77.

109. Ognjanovic S, Olivier M, Bergemann TL, Hainaut P. Sarcomas in tp53 germline mutation carriers. Cancer. 2012;118:1387-96.

110. Stinco G, Governatori G, Mattighello P, Patrone P. Multiple cutaneous neoplasms in a patient with Rothmund-Thomson syndrome: case report and published work review. J Dermatol. 2008:35:154-61.

111. Thomas DM, Ballinger ML. Etiologic, environmental and inherited risk factors in sarcomas. J Surg Oncol. 2015;111:490-5.

112. Mirabello L, Pfeiffer R, Murphy G, Daw NC, Patiño-Garcia A, Troisi RJ, Hoover RN, Douglass C, Schüz J, Craft AW, Savage SA. Height at diagnosis and birth-weight as risk factors for osteosarcoma. Cancer Causes Control. 2011;22:899-908.

113. Savage SA, Mirabello L, Wang Z, Gastier-Foster JM, Gorlick R, Khanna C, Flanagan AM, Tirabosco R, Andrulis IL, Wunder JS, et al. Genome-wide association study identifies two susceptibility loci for osteosarcoma. Nature Genet. 2013;45:799-803.

114. Yang J, Benyamin B, McEvoy BP, Gordon S, Henders AK, Nyholt DR, Madden PA, Heath AC, Martin NG, Montgomery GW, et al. Common SNPS explain a large proportion of the heritability for human height. Nature Genet. 2010;42:565-9.

115. Chen X, Bahrami A, Pappo A, Easton J, Dalton J, Hedlund E, Ellison D, Shurtleff S, Wu G, Wei L, et al. Recurrent somatic structural variations contribute to tumorigenesis in pediatric osteosarcoma. Cell Rep. 2014;7:104-12.

116. Srivastava S, Zou Z, Pirollo K, Blattner W, Chang EH. Germ-line transmission of a mutated p53 gene in a cancer-prone family with Li-fraumeni syndrome. Nature. 1990;348:747-9.

117. Zhang J, Walsh MF, Wu G, Edmonson MN, Gruber TA, Easton J, Hedges D, Ma X, Zhou X, Yergeau DA, et al. Germline mutations in predisposition genes in pediatric cancer. N Engl J Med. 2015;373:2336-46.

118. Poos K, Smida J, Nathrath M, Maugg D, Baumhoer D, Neumann A, Korsching E. Structuring osteosarcoma knowledge: An osteosarcomagene association database based on literature mining and manual annotation. Database. 2014. doi:10.1093/database/bau042.

119. Man T-K, Lu X-Y, Jaeweon K, Perlaky L, Harris CP, Shah S, Ladanyi M, Gorlick R, Lau CC, Rao PH. Genome-wide array comparative genomic hybridization analysis reveals distinct amplifications in osteosarcoma. BMC Cancer. 2004:4:45.

120. Xiao X, Wang W, Zhang H, Gao P, Fan B, Huang C, Fu J, Chen G, Shi $\mathrm{L}$, Zhu H, et al. Individualized chemotherapy for osteosarcoma and identification of gene mutations in osteosarcoma. Tumour Biol. 2015;36:2427-35

121. Yuan D, Liu B, Liu K, Zhu G, Dai Z, Xie Y. Overexpression of fibroblast activation protein and its clinical implications in patients with osteosarcoma. J Surg Oncol. 2013;108:157-62.

122. de Bruin EC, McGranahan N, Mitter R, Salm M, Wedge DC, Yates L, Jamal-Hanjani M, Shafi S, Murugaesu N, Rowan AJ, et al. Spatial and temporal diversity in genomic instability processes defines lung cancer evolution. Science. 2014;346:251-6.

123. Galanos P, Vougas K, Walter D, Polyzos A, Maya-Mendoza A, Haagensen EJ, Kokkalis A, Roumelioti F-M, Gagos S, Tzetis M, et al. Chronic p53-independent p21 expression causes genomic instability by deregulating replication licensing. Nat Cell Biol. 2016;18:777-89.

124. Al-Romaih K, Bayani J, Vorobyova J, Karaskova J, Park PC, Zielenska M, Squire JA. Chromosomal instability in osteosarcoma and its 
association with centrosome abnormalities. Cancer Genet Cytogenet. 2003;144:91-9.

125. Carter SL, Eklund AC, Kohane IS, Harris LN, Szallasi Z. A signature of chromosomal instability inferred from gene expression profiles predicts clinical outcome in multiple human cancers. Nature Genet. 2006;38:1043-8.

126. Ru G, Terracini B, Glickman LT. Host related risk factors for canine osteosarcoma. Vet J. 1998;156:31-9.

127. Phillips JC, Stephenson B, Hauck M, Dillberger J. Heritability and segregation analysis of osteosarcoma in the Scottish deerhound. Genomics. 2007:90:354-63.

128. von Holdt BM, Pollinger JP, Lohmueller KE, Han E, Parker HG, Quignon P, Degenhardt JD, Boyko AR, Earl DA, Auton A, et al. Genome-wide SNP and haplotype analyses reveal a rich history underlying dog domestication. Nature. 2010;464:898-902.

129. Caro JT, Marin LM, lazbik MC, Zaldivar-Lopez S, Borghese H, Couto CG Markers of iron metabolism in retired racing greyhounds with and without osteosarcoma. Vet Clin Pathol. 2013:42:360-3.

130. Lord LK, Yaissle JE, Marin L, Couto CG. Results of a web-based health survey of retired racing greyhounds. JVet Intern Med. 2007:21:1243-50.

131. Samaha J. The new complete Irish wolfhound. Howell Book House; 1991

132. Philipp U, Vollmar A, Häggström J, Thomas A, Distl O. Multiple loci are associated with dilated cardiomyopathy in Irish wolfhounds. PLOS ONE. 2012; 7:e36691.

133. Jansson M, Laikre L. Recent breeding history of dog breeds in Sweden: modest rates of inbreeding, extensive loss of genetic diversity and lack of correlation between inbreeding and health. J Anim Breed Genet. 2014:131:153-62.

134. The Kennel Club UK. Breed information centre-rottweiler. 2016. http://www.thekennelclub.org.uk/services/public/breed/display. aspx?id=5137. Accessed 29 Aug 2017.

135. American Kennel Club. Rottweiler. 2017. http://www.akc.org/dogbreeds/rottweiler/. Accessed 28 Aug 2017.

136. Karlsson EK, Sigurdsson S, Ivansson E, Thomas R, Elvers I, Wright J, Howald C, Tonomura N, Perloski M, Swofford R, et al. Genome-wide analyses implicate 33 loci in heritable dog osteosarcoma, including regulatory variants near CDKN2A/B. Genome Biol. 2013;14:R132.

137. Phillips JC, Lembcke L, Chamberlin T. A novel locus for canine osteosarcoma (OSA1) maps to CFA34, the canine orthologue of human 3q26. Genomics. 2010;96:220-7.

138. Dobson JM. Breed-predispositions to cancer in pedigree dogs. ISRN Vet Sci. 2013;2013:941275.

139. MacEwen EG, Pastor J, Kutzke J, Tsan R, Kurzman ID, Thamm DH, Wilson M, Radinsky R. IGF-1 receptor contributes to the malignant phenotype in human and canine osteosarcoma. J Cell Biochem. 2004;92:77-91.

140. McCleese JK, Bear MD, Kulp SK, Mazcko C, Khanna C, London CA. Met interacts with EGFR and Ron in canine osteosarcoma. Vet Comp Oncol. 2013;11:124-39.

141. Millanta F, Asproni P, Cancedda S, Vignoli M, Bacci B, Poli A. Immunohistochemical expression of COX-2, MPGES and EP2 receptor in normal and reactive canine bone and in canine osteosarcoma. J Comp Pathol. 2012;147:153-60.

142. Pang LY, Argyle SA, Kamida A, Morrison K, Argyle DJ. The long-acting COX-2 inhibitor mavacoxib (Trocoxil ${ }^{\mathrm{TM}}$ ) has anti-proliferative and proapoptotic effects on canine cancer cell lines and cancer stem cells. BMC Vet Res. 2014;10:184.

143. Shahi MH, York D, Gandour-Edwards R, Withers SS, Holt R, Rebhun RB. BMI1 is expressed in canine osteosarcoma and contributes to cell growth and chemotherapy resistance. PLoS ONE. 2015;10:e0131006.

144. Maniscalco L, lussich S, Morello E, Martano M, Gattino F, Miretti S, Biolatti B, Accornero P, Martignani E, Sánchez-Céspedes R, et al. Increased expression of insulin-like growth factor-1 receptor is correlated with worse survival in canine appendicular osteosarcoma. Vet J. 2015:205:272-80

145. Selvarajah GT, Kirpensteijn J, van Wolferen ME, Rao NAS, Fieten H, Mol JA. Gene expression profiling of canine osteosarcoma reveals genes associated with short and long survival times. Mol Cancer. 2009;8:72.

146. Selvarajah GT, Bonestroo FAS, Kirpensteijn J, Kik MJL, van der Zee R, van Eden W, Timmermans-Sprang EPM, Slob A, Mol JA. Heat shock protein expression analysis in canine osteosarcoma reveals HSP60 as a potentially relevant therapeutic target. Cell Stress Chaperon. 2013;18:607-22.

\section{Submit your next manuscript to BioMed Central and we will help you at every step:}

- We accept pre-submission inquiries

- Our selector tool helps you to find the most relevant journal

- We provide round the clock customer support

- Convenient online submission

- Thorough peer review

- Inclusion in PubMed and all major indexing services

- Maximum visibility for your research

Submit your manuscript at www.biomedcentral.com/submit
O Biomed Central 